\title{
Recombinant Human Bone Morphogenetic Protein-2 in Posterolateral Spinal Fusion: What's the Right Dose?
}

\author{
Martin Franz Hoffmann ${ }^{1,2}$, Clifford Barry Jones ${ }^{3,4}$, Debra Lynn Sietsema ${ }^{3,4}$ \\ ${ }^{1}$ Grand Rapids Medical Educational Partners, Grand Rapids, MI, USA \\ ${ }^{2}$ Department of Surgery, Berufsgenossenschaftliches Universitätsklinikum Bergmannshei, Bochum, Germany \\ ${ }^{3}$ Orthopaedic Associates of Michigan, Grand Rapids, MI, USA \\ ${ }^{4}$ The CORE Institute, Phoenix, AZ, USA
}

\section{Study Design: Single center retrospective cohort analysis.}

Purpose: The goal was to evaluate the influence of varying amount of recombinant human bone morphogenetic protein 2 (rhBMP-2) per level on fusion rates and complications in posterolateral spinal fusions.

Overview of Literature: rhBMP-2 has been utilized for lumbar posterolateral fusions for many years. Initial rhBMP-2 recommendations were $20 \mathrm{mg} / \mathrm{level}$ of fusion. Dose and concentration per level in current studies vary from 4.2 to $40 \mathrm{mg}$ and 1.5 to $2.0 \mathrm{mg} / \mathrm{mL}$, respectively. Variable fusion and complication rates have been reported.

Methods: Patients $(n=1,610)$ undergoing instrumented lumbar spinal fusion (2003-2009) with utilization of rhBMP-2 were retrospectively evaluated. Patient demographics, body mass index (BMI), comorbidities, number of levels, associated interbody fusion, and types of bone void filler were analyzed. Fusions rates and nonunions were subdivided into number of levels and amount of rhBMP-2 used per level.

Results: Patients ( $\mathrm{n}=559$ ) were evaluated with $58.5 \%$ females having an average age of 63 years, $\mathrm{BMl}$ of $31 \mathrm{~kg} / \mathrm{m}^{2}$. Number of levels fused ranged from 1 to 8 . rhBMP-2 averaged $7.3 \mathrm{mg} /$ level (range, 1.5-24 mg/level) based upon length of collagen sponge in relation to length of fusion levels. Patients with non-union formation had lower rhBMP-2 dose per level ( $p=0.016)$. A significant difference in non-union rate was found between patients undergoing fusion with $<6 \mathrm{mg} /$ level compared to those with $>6 \mathrm{mg} / \mathrm{level}(9.1 \% \mathrm{vs}$. $2.4 \%$, $\left.\chi^{2}=0.012\right)$. No significant differences were noted between $6-11.9 \mathrm{mg} / \mathrm{level}$ and $\geq 12 \mathrm{mg} / \mathrm{level}$. No threshold was found for seroma formation or bone overgrowth.

Conclusions: Previous recommendation of $20 \mathrm{mg} / \mathrm{level}$ of rhBMP-2 is more than what is required for predictable fusion rates of $98 \%$. No dose related increase of infection, seroma formation, and bone overgrowth has been found. In order to provide variable dosing and cost reduction, industry generated rhBMP-2 kit size should be optimized.

Keywords: Posterolateral lumbar fusion; Non-union; Complication; Recombinant human bone morphogenetic protein 2

Received Sep 14, 2015; Revised Oct 9, 2015; Accepted Oct 9, 2015

Corresponding author: Martin Franz Hoffmann

Berufsgenossenschaftliches Universitätsklinikum Bergmannsheil, Bochum, Bürkle-de-la-Camp-Platz 1, 44789 Bochum, Germany

Tel: +49-234-302-3391, Fax: +49-234-302-6542, E-mail: martinfhoffmann@gmx.net

*This study has been presented at the 26th Annual Meeting of the North American Spine Society. 


\section{Introduction}

Bone morphogenetic proteins (BMPs) discovery and identification were based on Urist's report of the ability of demineralized bone matrix to induce bone formation in extraskeletal locations [1]. Extensive evidence has supported the role of BMPs as regulators of bone induction, maintenance, and repair [2]. BMPs form a sub-group of proteins within the 43-member transforming growth factor- $\beta$ (TGF- $\beta$ ) superfamily. Currently, 16 BMPs have been identified [2,3], and not all of them seem to be capable of inducing bone formation; however, synergistic relations between different BMP molecules are probable [4]. Some even effectively antagonize the osteogenic activity of other BMPs [5].

Bone graft material and reliable fusion rates are an essential part of successful spinal fusions [6]. There are continued efforts to enhance the process of achieving spine fusion and to eliminate the need for the autogenous iliac bone graft harvests, which involves an additional surgical procedure. The option and use of osteobiologics to enhance fusion has therefore become an important part of these procedures [7]. As one of the BMPs, recombinant human bone morphogenetic protein 2 (rhBMP-2) (INFUSE, Medtronic, Memphis, TN, USA) is commercially available for clinical use when it was approved by the U.S. Food and Drug Administration (FDA) in 2002 for anterior lumbar spine fusions level L4 to S1 within a cage implant (FDA approval letter, July 2, 2002) and for the repair of symptomatic, posterolateral lumbar spine pseudoarthrosis (approval October 10th, 2008).

Despite the restricted label and with its associated warnings, the off-label use of BMPs for additional indications has become a trend. About $85 \%$ of the procedures using $\mathrm{BMP}$, including posterolateral fusions, were performed in an off-label basis [8]. rhBMP-2 in combination with bone void fillers with or without a combination with iliac crest autograft for posterolateral intertransverse process fusions has been practiced [9] and has become more accepted over time [8]. This may be because of larger amounts of bonegraft required for this procedure particularly in the setting of osteoporosis or poor bone quality. The adjunctive use of rhBMP-2 has been reported to result in larger and more consistent fusion masses [10].

For the procedure involving rhBMP-2, an initial study recommended $20 \mathrm{mg}$ of the drug per level [9], but for lumbar fusions no consistent dosage per level can be found in the current literature. Dosage and drug concentrations used per level have varied from 4.2 to $40 \mathrm{mg}$ and 1.5 to $2.0 \mathrm{mg} / \mathrm{mL}$, respectively [9-12]. Despite the desire for surgeons and patients to avoid pseudoarthrosis and iliac crest bone graft harvest morbidity, the cost of rhBMP-2 treatment $[12,13]$ and possible complications from its use $[7,14]$ remain an important concern, and multiple studies have been performed to lower rhBMP-2 dose without sacrificing reliable fusion rates $[15,16]$. Several carriers for rhBMP-2 have been evaluated to optimize drug delivery at the fusion site and to increase safety [17]. For example, Barnes et al. [16] reduced necessary rhBMP-2 dose for spine fusion in combining rhBMP-2 with an osteoconductive bulking agent in non-human primates.

To our knowledge, no clinical study has been performed to define the amount of rhBMP-2 necessary to achieve reliable fusion rates in posterolateral spine fusion and in addition consider the complication rates. The purpose of this study was to compare complication rates in patients who underwent instrumented posterolateral lumbar fusion utilizing various amounts of rhBMP-2 per level.

\section{Materials and Methods}

The protocol was reviewed and approved by the Spectrum Health Institutional Review Board (SH IRB \#: 2010-197) of our institution. Between 2003 and 2009, 1,610 patients underwent instrumented lumbar posterolateral fusion with the addition of rhBMP-2 performed by five orthopedic spine surgeons in a tertiary referral spine center. Follow-up was performed in one single orthopedic institution. We retrospectively reviewed operative reports, radiographs and patient charts. One thousand and fifty-one patients were excluded due to being younger than 18 years old at the time of surgery $(\mathrm{n}=2)$, having an additional bone-stimulator $(\mathrm{n}=16)$, an additional lumbar interbody fusion ( $n=637$ ), having number of levels fused greater than eight $(n=16)$, having non-instrumented fusion $(\mathrm{n}=156)$, having fracture as a surgical indication $(\mathrm{n}=62)$, having pelvic fixation $(n=37)$, having a follow up with a neurosurgeon $(\mathrm{n}=10)$, and having a follow-up of less than 6 months ( $\mathrm{n}=113)$.

We identified 559 patients with a mean age of 63 years (range, 18-89 years) who underwent instrumented lumbar posterolateral fusions with supplementation of rhBMP-2. The study group consisted of 232 males (41.5\%) and 327 females (58.5\%) with an average body mass index 
Table 1. Contributing factors and comorbidities

\begin{tabular}{lc}
$\begin{array}{l}\text { Contributing factors } \\
\text { (more than one possible) }\end{array}$ & Number (\%) \\
\hline Diabetes & $101(18.1)$ \\
\hline Cardiovascular disease & $309(55.3)$ \\
Respiratory disease & $113(20.2)$ \\
\hline Smoking & $42(7.8)$ \\
\hline Past smokers & $153(27.4)$ \\
\hline Allergies & $275(49.2)$ \\
\hline Steroid medication & $141(25.2)$ \\
\hline NSAID medication & $206(36.9)$ \\
\hline
\end{tabular}

NSAID, nonsteroidal anti-inflammatory drug.

Table 2. Bone graft and extender utilization

\begin{tabular}{lc}
$\begin{array}{l}\text { Bone graft and extenders } \\
\text { (multiple possible) }\end{array}$ & Number $(\%)$ \\
\hline Iliac crest bone graft & $6(1.1)$ \\
\hline Bone marrow aspirate & $56(10.0)$ \\
\hline Allograft & $449(80.3)$ \\
Mastergraft & $444(79.4)$ \\
\hline Pro Osteon & $7(1.3)$ \\
Demineralized bone matrix & $23(4.1)$ \\
\hline Magellan & $9(1.6)$ \\
\hline
\end{tabular}

(BMI) of $31.3 \mathrm{~kg} / \mathrm{m}^{2}$ (range, $18-57 \mathrm{~kg} / \mathrm{m}^{2}$ ). Mean length of hospital stay was 4.8 days (range, 2-21 days). Comorbidities and contributing factors were recorded (Table 1).

Patients with lumbar stenosis and neurogenic claudication presenting for lumbar posterolateral fusion had persistent symptoms refractory to non-operative treatment that included non-steroidal pain medication, physical therapy, and/or spinal injections. Surgical treatment was performed in accordance with the surgeon's best knowledge. Therefore bone graft and bone graft extenders were used at the surgeon's discretion (Table 2). All patients underwent local autografting of varying amounts.

The bone morphogenetic protein utilized was rhBMP-2 (Medtronic). The preparation was performed in accordance with the manufacturer's recommendation. In general, before the protein was applied to the bovine collagen sponge, the sponge was cut lengthwise (long and skinny) or sideways (short and fat) depending on the number of levels fused or the size of the patient. The length of the intertransverse process distance determined the size and

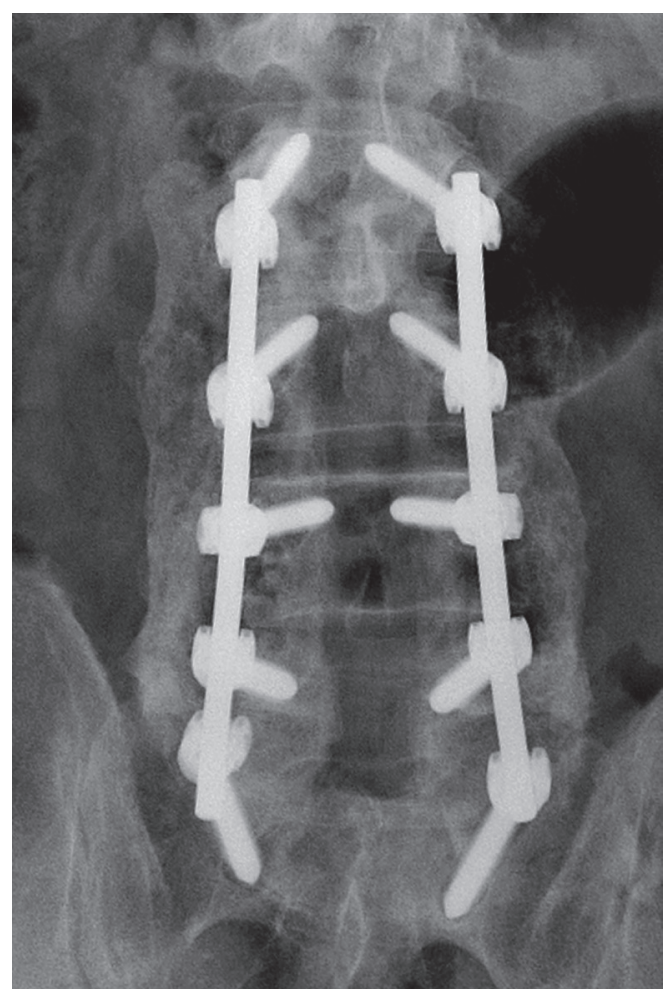

Fig. 1. Posterolateral fusion on plain radiograph.

number of rhBMP-2 kits. The sponge with corresponding rhBMP-2 had to touch each transverse process corresponding to the levels being fused. The order of rhBMP-2 insertion deep to or superficial to posterior elements was variable and surgeon dependent. Complications due to the procedure or as a repeat and/or revised procedure, if necessary, were recorded. For comparison of complication rates, four groups were created (Group 1: $<4.0 \mathrm{mg} /$ level; Group 2: 4-5.9 mg/level; Group 3: 6-11.9 mg/level; Group 4: $\geq 12 \mathrm{mg} /$ level).

The mean follow-up period was 17 months (range, 6-69 months). During that time, radiographic evaluation was performed as well as a computed tomography scan and magnetic resonance imaging if necessary. One author (M.F.H.), who did not perform any of the surgeries and was blinded to the rhBMP-2 amount used, independently examined all the plain radiographic images (Fig. 1) using adapted criteria for plain radiographs by Singh et al. [10] for fusion rate and quality (Table 3 ). We therefore classified the fusion of each attempted level according to the operative report and classified each level for fusion and quality on each side. The results were added, and divided by number of levels.

Data was analyzed using PASW ver. 18 (IBM Co., Ar- 
Table 3. Radiographic criteria for fusion assessment and fusion quality

\begin{tabular}{|c|c|c|c|c|c|}
\hline \multicolumn{3}{|c|}{ Determination of fusion } & \multicolumn{3}{|c|}{ Subjective assessment of fusion quality } \\
\hline \multicolumn{3}{|c|}{ Radiographic criteria } & \multicolumn{3}{|c|}{ Radiographic findings } \\
\hline I & \multicolumn{2}{|c|}{ Bridging trabecular bone } & A & \multicolumn{2}{|c|}{$\begin{array}{l}\text { large fusion mass extending beyond lateral edge of } \\
\text { original transverse process }\end{array}$} \\
\hline$\|$ & \multicolumn{2}{|c|}{ Cortication of the peripheral edges of the fusion mass } & B & \multicolumn{2}{|c|}{ Convex appearance of lateral fusion mass } \\
\hline III & \multicolumn{2}{|c|}{ Presence of an identifiable cleft } & C & \multicolumn{2}{|c|}{ Homogenous bone quality within fusion mass } \\
\hline \multicolumn{2}{|c|}{ Fusion assessment } & Radiographic criteria present & \multicolumn{2}{|c|}{ Fusion quality } & Radiographic criteria present \\
\hline 4 & Definitely fused & Presence of I and II, absence of III & & & \\
\hline 3 & Probably fused & Presence of I, partial II, absence of III & 3 & Excellent & Presence of $A, B$ and $C$ \\
\hline 2 & Indeterminate & Presence of I or II and incomplete III & 2 & Good & $\begin{array}{l}\text { Presence of two out of three } \\
\text { radiographic findings }\end{array}$ \\
\hline 1 & Probably not fused & Absence of I, II and presence of incomplete III & 1 & Fair & $\begin{array}{l}\text { Presence of one out of three } \\
\text { radiographic findings }\end{array}$ \\
\hline 0 & Definitely not fused & Presence of III & 0 & Poor & $\begin{array}{l}\text { Absence of all three radiographic } \\
\text { findings }\end{array}$ \\
\hline
\end{tabular}

monk NY, USA) and descriptive statistical analysis was performed. Chi-square and $t$-tests were used to compare those that developed complications versus those that did not, based on demographic data and potential contributing risk factors. When an unequal variance of means was present, a Wilcoxon 2-sample test was used to determine differences in analysis. Mann-Whitney $U$ tests and Kruskal-Wallis tests were used to determine difference in the categorical groups of rhBMP-2 dose per level for presence of complications of nonunion, infection, and fluid collection and the mean measure of fusion assessment and quality, respectively. Pearson's correlation coefficient $(r)$ was used to determine relationships between demographic variables and complications. A multivariate logistic stepwise regression controlling for levels fused was used to determine independent demographic variables that predicted complications such as nonunion, infection, and fluid collection.

\section{Results}

We studied 1,189 fused levels in 559 patients. The average number of levels fused was 2.1 (Table 4 ). The average amount of total rhBMP-2 per patient was $12.6 \mathrm{mg}$ (range, $4.2-48 \mathrm{mg}$ ). The average dose per level was $7.3 \mathrm{mg}$ (range, $1.5-24 \mathrm{mg})$.

In our patient sample, 21 of 559 patients (3.8\%) underwent repeat surgery for non-union. We found an average of 7.4 mg rhBMP-2 per level for those who developed a stable
Table 4. Numbers of levels fused

\begin{tabular}{lcc}
$\begin{array}{l}\text { No. of levels } \\
\text { fused }\end{array}$ & $\begin{array}{c}\text { No. of patients } \\
(\%)\end{array}$ & $\begin{array}{c}\text { Average dose per } \\
\text { level (mg) }\end{array}$ \\
\hline 1 & $169(30.2)$ & 12.0 \\
2 & $244(43.6)$ & 6.1 \\
\hline 3 & $92(16.5)$ & 4.3 \\
\hline 4 & $35(6.3)$ & 3.8 \\
\hline 5 & $8(1.4)$ & 2.7 \\
\hline 6 & $5(0.9)$ & 2.4 \\
\hline 7 & $2(0.4)$ & 3.4 \\
\hline 8 & $4(0.7)$ & 1.9 \\
\hline
\end{tabular}

fusion compared to an average of $6.0 \mathrm{mg}$ rhBMP-2 for those who developed a non-union $(Z=-2.401, p=0.016)$. Nonunion rate was not related to gender $\left(\chi^{2}=0.069\right)$, having diabetes $\left(\chi^{2}=0.493\right)$, being a smoker $(r=0.084$, $p=0.059)$, preoperative steroid medication $\left(\chi^{2}=0.842\right)$, or preoperative NSAID medication $\left(\chi^{2}=0.061\right)$. Weak correlations were found between age $(r=0.106, p=0.020)$ and BMI ( $r=0.117, p=0.007)$. Being female and having a high BMI were predictive of nonunion development $(\mathrm{F}=6.197$ and $p=0.002$ ).

Patients with postoperative infections $(n=18)$ underwent fusion utilizing an average of $6.0 \mathrm{mg}$ rhBMP-2 per level compared to $7.4 \mathrm{mg}$ rhBMP-2 for those who had no infection $(Z=-1.464, p=0.143)$. No association was found between infection and age $(r=-0.007, p=0.863)$, having 
diabetes $\left(\chi^{2}=0.625\right)$, or receiving preoperative NSAID or steroids $\left(\chi^{2}=0.918, \chi^{2}=0.975\right.$, respectively). Infection rate in non-smoking patients was $2.5 \%$, while current and past smokers had an infection rate of $5.1 \%\left(\chi^{2}=0.014\right)$. Male patients had more infections than females $\left(\chi^{2}=0.030\right)$. Obese patients (those with a higher BMI) had increased rates of infection $(r=0.156, p=0.007)$. Total dose of BMP, increasing BMI, and numbers of levels fused correlated with higher infection rates $(\mathrm{F}=10.094, p<0.001)$.

There was no difference in rhBMP-2 dose per level for patients who developed postoperative fluid collection compared to those who had no postoperative fluid collection (6.5 mg, $7.4 \mathrm{mg}$, respectively). No association was found between fluid collection and age $(r=-0.018$, $p=0.663)$, gender $\left(\chi^{2}=0.457\right)$, presence of diabetes or higher BMI $\left(\chi^{2}=0.625 ; r=-0.082, p=0.058\right.$, respectively $)$.
Steroid or NSAID medication use did not influence development of fluid collections $\left(\chi^{2}=0.078, \chi^{2}=0.172\right.$, respectively); however, smoking predicted fluid collection $(\mathrm{F}=5.791, p=0.017)$.

Bone overgrowth was radiographically diagnosed in eight patients. The amount of rhBMP-2 per level in those patients was lower but not significantly $(p=0.143)$. Comparing the four groups, significant differences were found in nonunion rates for patients who underwent fusion with 4.0-5.9 mg/level compared with those who underwent fusion with $\geq 6.0 \mathrm{mg} /$ level (Fig. 2).

A comparable mean radiographic fusion rate and quality was found when comparing groups with $<4.0 \mathrm{mg}, 4.0$ $5.9 \mathrm{mg}$, and $6.0-11.9 \mathrm{mg}$, and $\geq 12.0 \mathrm{mg}$ of rhBMP-2 (Table $5)$. Our data shows an increase in radiographic fusion $(p=0.005)$, but no further improvement in fusion quality

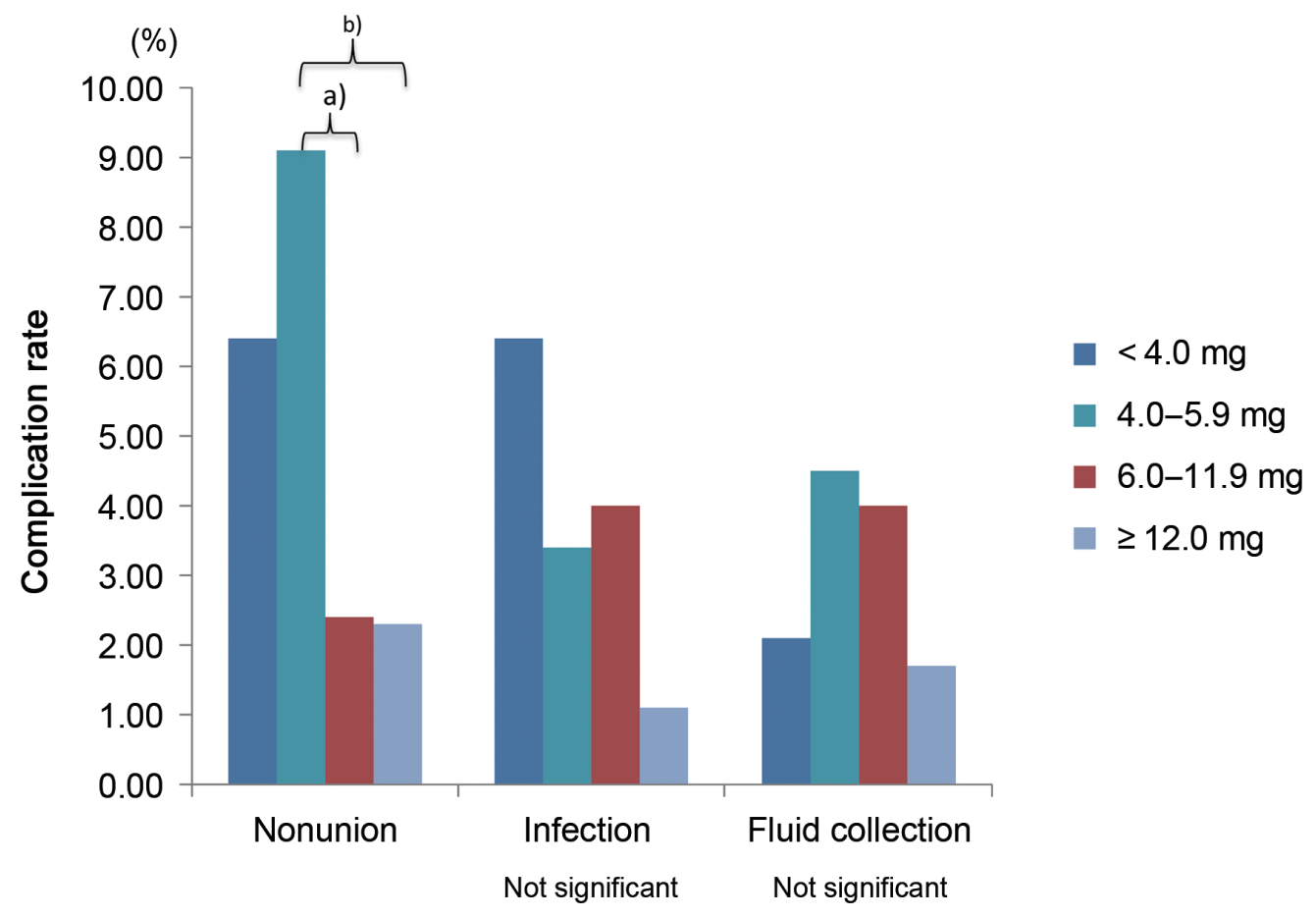

Fig. 2. Complication rates related to dose per level. ${ }^{\text {al }} p=0.017$; ${ }^{\text {b) }} p=0.012$.

Table 5. Mean radiographic fusion and fusion quality assessment scores

\begin{tabular}{lccc} 
rhBMP-2 dosage per level & Number & Radiographic fusion assessment & Radiographic fusion quality \\
$<4.0 \mathrm{mg}$ & $28 / 47$ & 1.9 & 3.1 \\
\hline $4.0-5.9 \mathrm{mg}$ & $58 / 88$ & 6.0 & 3.6 \\
$6.0-11.9 \mathrm{mg}$ & $176 / 250$ & 6.0 & 3.6 \\
$>12 \mathrm{mg}$ & $121 / 174$ & 6.1 & 3.6 \\
\hline
\end{tabular}

rhBMP-2, recombinant human bone morphogenetic protein 2 . 
( $p=0.080)$ with higher rhBMP-2 doses.

\section{Discussion}

Posterolateral arthrodesis is an integral component of the surgical management of degenerative disease of the lumbar spine. Excellent or good results in clinical outcome considering relief of pain and increase in activity after successful fusion were found in $85 \%$ of the patients [6]. However, surgeons and researcher are still in search of a better fusion procedure and supplement. Iliac crest bone graft is currently the gold standard for intertransverse process or posterolateral fusions. Fischgrund et al. [6] demonstrated better results in patients who underwent additional posterior instrumentation. Despite improved mechanical stability with instrumentation, multiple methods have been developed to optimize the biological environment for fusion to occur.

Allograft bone derived from fresh frozen femoral heads seems to have similar properties compared to iliac crest bone graft [18] but includes the risk for disease transmission [14]. Processing allograft bone by acid extraction results in loss of the mineralized components (demineralized bone matrix). Collagen and noncollagenous proteins, including growth factors are preserved. Therefore, demineralized bone matrix offers growth factors, including BMPs, at very low and inconsistent concentrations [19]. The most promising adjuncts are BMPs, which have been proven to induce bone formation and increase fusion rates $[9,20]$. As a result, the use of BMPs in spinal fusions has increased to $25 \%$ nationally (2006) [13].

Based on the goal of achieving the highest possible fusion rates, different doses of rhBMP-2 per level have been used in the past. Our findings indicate that 6 to $12 \mathrm{mg}$ rhBMP-2 per level provide a large bridging fusion mass with minimal complications. Early studies in nonhuman primates suggested 18 to $32 \mathrm{mg}$ rhBMP-2 per side resulting in 36 to $64 \mathrm{mg}$ rhBMP-2 per level was needed to achieve solid fusion [21]. Subsequently, multiple clinical studies have been performed using $40 \mathrm{mg}$ per level fused leading to fusion rates of up to $100 \%[9,11,22]$. But there has been a growing concern of complications and adverse effects. A systematic literature review showed that utilization of BMP in the lumbar spine could be associated with radiographic graft resorption, extradiscal, ectopic, and heterotopic bone formation, radiculopathies, epidural cyst formation, and seromas [7].
Our finding of $2.3 \%$ nonunion rate in patients who underwent instrumented posterolateral fusion in combination with $\geq 12 \mathrm{mg}$ rhBMP-2 per level is comparable to Singh et al. [10] who found a $97 \%$ fusion rate for these patients. In comparing nonunion rates, according to our findings, there seems to be no significant differences for fusion rates for 6 to $11.9 \mathrm{mg}$ rhBMP-2 compared to $\geq 12$ mg rhBMP-2 per level. We found similar pseudoarthrosis rates in revision surgeries, which is the most accurate measurement tool according to previous studies $[23,24]$. Aware of the fact that radiographic findings are about $70 \%$ accurate $[23,24]$, radiographic evaluation also did not reveal significant differences in fusion assessment or fusion quality for procedures using more than $4 \mathrm{mg} / \mathrm{level}$. However, in our study population further reduction of rhBMP-2 dose per level resulted in a significant increase in non-union rates.

We did not find higher rates of infection or fluid collection in patients undergoing fusion with higher levels of rhBMP-2. Infection rate correlates to the number of levels fused and BMI. Therefore, size of surgical approach and soft tissue damage seems to be more important than rhBMP-2 dose used. Development of a fluid collection was not related to rhBMP-2 dose, and there seems to be no correlation or threshold of drug use to prevent this complication. Similar findings were reported for swelling complications associated with rhBMP-2 in the anterior cervical spine where a dose of $0.6 \mathrm{mg}$ per level resulted in $27.5 \%$ having significant swelling events [25]. It is hypothesized that rhBMP-2 leads to inflammation, resulting in edema and seroma/hematoma formation [26]. These findings have been related to high rhBMP-2 dosages [27] as well as osteoclastic activity in interbody fusions [28].

rhBMP-2 is a recombinant human protein delivered on an absorbable sponge generated from bovine Type I collagen. The development of antibody response to either of these proteins is possible. However, serology testing has demonstrated no significant authentic immunologic antibody response to either rhBMP-2 or Type I bovine collagen [17], and re-exposure to these proteins does not lead to significant symptomatic antibody formation [29]. Nevertheless, further studies concerning fluid collections after BMP utilization are therefore warranted.

In our study, a wide variety of grafts and bone void fillers were used. In accordance with previous studies in nonhuman primates [21] fusion depends not only on rhBMP-2 dose but also on the use of posterior elements, 
iliac crest autograft, allograft, and bone void fillers. Hence, the question arises whether fusion cannot be achieved by using solely autograft and supplements.

The major limitation of this study was its retrospective design. The surgical outcome or complications were not compared to a contemporaneous control group. Reporting of small symptomatic seromas were included in this study, but if they did not cause painful or neurological symptoms, they probably were not diagnosed or recognized as seromas. In this study, three seromas underwent percutaneous fluoroscopically guided aspiration. There may have been a higher number of small undiagnosed seromas with prolonged postoperative pain. Radiculitis, as a complication attributed to rhBMP-2 utilization, has not been addressed in this study due to lack of practical tools to distinguish retrospectively between radiculitis and prolonged postoperative pain.

The strength of this study was the number of patients included and the homogeneity of the procedures performed. All surgeries were performed by five boardcertified, experienced spine surgeons who had consistent treatment philosophies. Therefore this study provides a guide for rates and types of the complications seen with respect to different rhBMP-2 doses used in posterolateral spinal fusion surgeries.

\section{Conclusions}

According to our findings, the previous recommendation of $20 \mathrm{mg} /$ level of rhBMP-2 is more than what is required clinically for predictable fusion rates of $98 \%$. However for fusions utilizing less than $6 \mathrm{mg}$ rhBMP-2 per level nonunion rates increase for instrumented posterolateral lumbar fusion. In order to provide variable dosing and cost reduction, the available manufacturer generated rhBMP-2 kit sizes should be optimized for variable dosing.

\section{Conflict of Interest}

No potential conflict of interest relevant to this article was reported.

\section{Acknowledgments}

We thank spine surgeons, J. Todd Brown, MD, Kenneth J. Easton, MD, Scott S. Russo, MD, and James R. Stubbart, $\mathrm{MD}$, for their surgical expertise and contribution for this study. Additionally, we appreciate Patrick Bowman, BA, for his assistance in data analysis.

\section{References}

1. Urist MR. Bone: formation by autoinduction. Science 1965;150:893-9.

2. Wozney JM, Rosen V. Bone morphogenetic protein and bone morphogenetic protein gene family in bone formation and repair. Clin Orthop Relat Res 1998; (346): 26-37.

3. Kim M, Choe S. BMPs and their clinical potentials. BMB Rep 2011;44:619-34.

4. Celeste AJ, Iannazzi JA, Taylor RC, et al. Identification of transforming growth factor beta family members present in bone-inductive protein purified from bovine bone. Proc Natl Acad Sci U S A 1990;87:98437.

5. Cheng H, Jiang W, Phillips FM, et al. Osteogenic activity of the fourteen types of human bone morphogenetic proteins (BMPs). J Bone Joint Surg Am 2003; 85:1544-52.

6. Fischgrund JS, Mackay M, Herkowitz HN, Brower R, Montgomery DM, Kurz LT. 1997 Volvo Award winner in clinical studies. Degenerative lumbar spondylolisthesis with spinal stenosis: a prospective, randomized study comparing decompressive laminectomy and arthrodesis with and without spinal instrumentation. Spine (Phila Pa 1976) 1997;22:280712.

7. Mroz TE, Wang JC, Hashimoto R, Norvell DC. Complications related to osteobiologics use in spine surgery: a systematic review. Spine (Phila Pa 1976) 2010; 35:S86-104.

8. Ong KL, Villarraga ML, Lau E, Carreon LY, Kurtz SM, Glassman SD. Off-label use of bone morphogenetic proteins in the United States using administrative data. Spine (Phila Pa 1976) 2010;35:1794-800.

9. Boden SD, Kang J, Sandhu H, Heller JG. Use of recombinant human bone morphogenetic protein-2 to achieve posterolateral lumbar spine fusion in humans: a prospective, randomized clinical pilot trial: 2002 Volvo Award in clinical studies. Spine (Phila Pa 1976) 2002;27:2662-73.

10. Singh K, Smucker JD, Gill S, Boden SD. Use of recombinant human bone morphogenetic protein-2 as an adjunct in posterolateral lumbar spine fusion: a 
prospective CT-scan analysis at one and two years. J Spinal Disord Tech 2006;19:416-23.

11. Dimar JR 2nd, Glassman SD, Burkus JK, Pryor PW, Hardacker JW, Carreon LY. Clinical and radiographic analysis of an optimized rhBMP-2 formulation as an autograft replacement in posterolateral lumbar spine arthrodesis. J Bone Joint Surg Am 2009;91:1377-86.

12. Glassman SD, Carreon LY, Campbell MJ, et al. The perioperative cost of Infuse bone graft in posterolateral lumbar spine fusion. Spine J 2008;8:443-8.

13. Cahill KS, Chi JH, Day A, Claus EB. Prevalence, complications, and hospital charges associated with use of bone-morphogenetic proteins in spinal fusion procedures. JAMA 2009;302:58-66.

14. Glassman SD, Howard JM, Sweet A, Carreon LY. Complications and concerns with osteobiologics for spine fusion in clinical practice. Spine (Phila $\mathrm{Pa}$ 1976) 2010;35:1621-8.

15. Akamaru T, Suh D, Boden SD, Kim HS, Minamide A, Louis-Ugbo J. Simple carrier matrix modifications can enhance delivery of recombinant human bone morphogenetic protein-2 for posterolateral spine fusion. Spine (Phila Pa 1976) 2003;28:429-34.

16. Barnes B, Boden SD, Louis-Ugbo J, et al. Lower dose of rhBMP-2 achieves spine fusion when combined with an osteoconductive bulking agent in non-human primates. Spine (Phila Pa 1976) 2005;30:112733.

17. McKay B, Sandhu HS. Use of recombinant human bone morphogenetic protein-2 in spinal fusion applications. Spine (Phila Pa 1976) 2002;27:S66-85.

18. Gibson S, McLeod I, Wardlaw D, Urbaniak S. Allograft versus autograft in instrumented posterolateral lumbar spinal fusion: a randomized control trial. Spine (Phila Pa 1976) 2002;27:1599-603.

19. Bae HW, Zhao L, Kanim LE, Wong P, Delamarter $\mathrm{RB}$, Dawson EG. Intervariability and intravariability of bone morphogenetic proteins in commercially available demineralized bone matrix products. Spine (Phila Pa 1976) 2006;31:1299-306.

20. Vaccaro AR, Lawrence JP, Patel T, et al. The safety and efficacy of OP-1 (rhBMP-7) as a replacement for iliac crest autograft in posterolateral lumbar arthrod- esis: a long-term ( $>4$ years) pivotal study. Spine (Phila Pa 1976) 2008;33:2850-62.

21. Martin GJ Jr, Boden SD, Marone MA, Moskovitz PA. Posterolateral intertransverse process spinal arthrodesis with rhBMP-2 in a nonhuman primate: important lessons learned regarding dose, carrier, and safety. J Spinal Disord 1999;12:179-86.

22. Dimar JR, Glassman SD, Burkus KJ, Carreon LY. Clinical outcomes and fusion success at 2 years of single-level instrumented posterolateral fusions with recombinant human bone morphogenetic protein-2/ compression resistant matrix versus iliac crest bone graft. Spine (Phila Pa 1976) 2006;31:2534-9.

23. Blumenthal SL, Gill K. Can lumbar spine radiographs accurately determine fusion in postoperative patients? Correlation of routine radiographs with a second surgical look at lumbar fusions. Spine (Phila Pa 1976) 1993;18:1186-9.

24. Kant AP, Daum WJ, Dean SM, Uchida T. Evaluation of lumbar spine fusion. Plain radiographs versus direct surgical exploration and observation. Spine (Phila Pa 1976) 1995;20:2313-7.

25. Smucker JD, Rhee JM, Singh K, Yoon ST, Heller JG. Increased swelling complications associated with offlabel usage of rhBMP-2 in the anterior cervical spine. Spine (Phila Pa 1976) 2006;31:2813-9.

26. Shields LB, Raque GH, Glassman SD, et al. Adverse effects associated with high-dose recombinant human bone morphogenetic protein-2 use in anterior cervical spine fusion. Spine (Phila Pa 1976) 2006;31:542-7.

27. Tumialan LM, Pan J, Rodts GE, Mummaneni PV. The safety and efficacy of anterior cervical discectomy and fusion with polyetheretherketone spacer and recombinant human bone morphogenetic protein-2: a review of 200 patients. J Neurosurg Spine 2008;8:52935.

28. Meisel HJ, Schnoring M, Hohaus C, et al. Posterior lumbar interbody fusion using rhBMP-2. Eur Spine J 2008;17:1735-44.

29. Singh K, Dumonski M, Stanley T, Ponnappan R, Phillips FM. Repeat use of human recombinant bone morphogenetic protein-2 for second level lumbar arthrodesis. Spine (Phila Pa 1976) 2011;36:192-6. 